\title{
Climate Change, Energy Demand and Market Power in a General Equilibrium Model of the World Economy
}

\author{
Francesco Bosello* and Roberto Roson ${ }^{\circ}$
}

\author{
PRELIMINARY DRAFT
}

\begin{abstract}
Future energy demand will be affected by changes in prices and income, but also by other factors, like temperature levels.

This paper draws upon an econometric study, disentangling the contribution of temperature in the determination of the annual regional demand for energy goods. Combining estimates of temperature elasticities with scenarios of future climate change, it is possible to assess variations in energy demand induced (directly) by the global warming.

We use this information to simulate a change in the demand structure of households in a CGE model of the world economy, in a set of assessment exercises. The changing demand structure triggers a structural adjustment process, influencing trade flows, regional competitiveness of industries and regions, and welfare. We also consider the possible existence of imperfect competition in the energy markets, analyzing the impact of changes in energy demand with an alternative model version, in which energy industries are modeled as Cournot oligopolies.
\end{abstract}

JEL Codes : D58, F12, Q43, Q54

Keywords: Climate Change, Energy, Computable General Equilibrium Models, Imperfect Competition.

\section{Introduction}

Climate change is expected to affect energy markets in various ways, both directly and indirectly. Indirect effects will operate through environmental policies, aimed at changing the consumption pattern of energy goods and/or sustaining the development and diffusion of cleaner technologies.

Direct effects are also important. Energy demand will be affected by temperature changes, because higher temperatures imply less energy for heating and more demand for cooling, in addition to variations in the demand for energy as a

* Fondazione ENI Enrico Mattei, Venice, Italy.

- Fondazione ENI Enrico Mattei and Ca'Foscari University, Venice, Italy. E-mail roson@unive.it . 
production factor. We therefore expect a U-shaped relationship between temperature and energy demand. We also expect changes in the composition of demand, between alternative energy goods. ${ }^{1}$

This paper analyzes the direct economic impact of climate change on energy demand. From a macroeconomic perspective, the climate impact will not affect primary resources of the various regional economies, but rather the structure of industrial and households demand for goods and services. In other words, we consider a shock that could increase or decrease the demand for energy goods at constant prices and income.

To model the adjustment process, we use a Computable General Equilibrium model of the world economy, based on the GTAP data base and model. In our setting, the change in temperature leads to a forced reallocation of budget for firms and consumers. We therefore compare a baseline general equilibrium for the world economy, with a counterfactual equilibrium, generated by changes in tastes and technology. An analysis of this counterfactual equilibrium highlights the structural adjustment processes and the distributional effects involved.

This exercise relies on a econometric analysis of the relationship between average temperature levels and long run demand for energy goods, by Bigano et at. (2006). The methodology and the findings of this study are summarized in section 2 . Section 3 explains how estimates of temperature elasticities have been used as input parameters for a simulation exercise with a CGE model of the world economy, and illustrates the main results. Section 4 considers whether, and how, results could change if the existence of market power in energy industries is explicitly taken into account in the model. A final section draws some conclusions.

\section{Estimating the relationship between energy demand and temperature levels}

A number of studies (e.g., Pardo et al., 2002) have investigated the influence of temperature on energy demand, but mainly at the regional/seasonal scale. To our knowledge, the recent paper by Andrea Bigano, Francesco Bosello and Giuseppe Marano (2006) is the first attempt at estimating the (long-run) temperature elasticities of energy demand, in terms of average annual temperatures and national consumption.

The General Method of Moments is used to estimate parameters for an equation like:

$$
y_{i t}=\rho y_{i, t-1}+x^{\prime}{ }_{i t} \beta+c_{i}+u_{i t}
$$

where:

$i$ is an index over regions/countries;

$t$ is an index over time;

$y$ is consumption of a specific energy vector: coal, natural gas, electricity, oil and oil

1 Effects of temperature on energy demand are one type of direct economic impact of climate change. Other impacts include: variations in sea/ocean levels (Bosello et al., 2004), extreme events (Calzadilla et al., 2005), human health (Bosello et al., 2006), touristic flows (Berrittella et al., 2005a), water availability (Berrittella et al., 2005b), transportation, energy demand, and others. 
products (index over goods omitted) by three separate sectors: households, industry and services (index over sectors omitted);

$x$ is a set of regressors: real GDP, average market price and average yearly

temperature;

$c$ is a region-specific fixed factor;

$u$ is the standard error term.

As far as temperature is concerned, the main empirical finding is that household demand is responsive to changes in temperature, generally through an inverse relationship, and with long time lags. On the other hand, the temperature elasticity of energy demand by the industry and service sectors is, in most cases, small and not statistically significant. Table 1 reports the estimated values for the temperature elasticities.

Table 1 - Estimated temperature elasticities

\begin{tabular}{||c|c|c|c||}
\hline \multirow{2}{*}{$\begin{array}{c}\text { Energy } \\
\text { Vector }\end{array}$} & \multicolumn{3}{|c|}{ Sector } \\
\cline { 2 - 4 } & Households & Industrial & Services \\
\hline Coal & 2.845 & -0.385 & -2.548 \\
\hline Electricity & -0.576 & 0.053 & -0.198 \\
\hline Natural Gas & -1.823 & 0.061 & -0.1534 \\
\hline Oil & - & -0.629 & - \\
\hline $\begin{array}{l}\text { Oil } \\
\text { Products }\end{array}$ & -3.055 & -0.342 & -2.134 \\
\hline
\end{tabular}

Results like those of Table 1 can be usefully combined with scenarios of climate change. For example, we considered the regional change in temperature 2000-2050 estimated by Giorgi and Mearns (2002), to get regional variations in households demand for energy goods at the year 2050, directly induced by the global warming. Results are reported in Table $2 .^{2}$

2 Region acronyms as follows: USA - U.S.A., EU - European Union, EEFSU - Eastern Europe and Former Soviet Union, JPN - Japan, RoA1 - Rest of Annex 1 countries in the Kyoto Protocol (developed countries), EEX - Energy exporting countries, CHIND - China and India, RoW - Rest of the World. 
Table 2 -Changes in temperature and household demand for energy goods

\begin{tabular}{|c|c|c|c|c|c|}
\hline \multirow{2}{*}{ Regions } & \multirow{2}{*}{$\begin{array}{l}\% \text { Var. in } \\
\text { regional average } \\
\text { temperature } \\
(2000-2050){ }^{\circ} \mathrm{C}\end{array}$} & \multicolumn{4}{|c|}{$\begin{array}{c}\text { Ex-ante } \% \text { increase in household demand } \\
\text { for energy commodities }\end{array}$} \\
\hline & & Coal & Nat. Gas & Oil Prod. & Electricity \\
\hline USA & 5.329 & 15.162 & -9.715 & -16.281 & -3.070 \\
\hline EU & 5.084 & 14.465 & -9.268 & -15.532 & -2.928 \\
\hline EEFSU & 10.305 & 29.317 & -18.786 & -31.481 & -5.936 \\
\hline JPN & 4.501 & 12.806 & -8.206 & -13.751 & -2.593 \\
\hline RoA1 & 5.239 & 14.906 & -9.551 & -16.006 & -3.018 \\
\hline EEX & 2.768 & 7.875 & -5.046 & -8.456 & -1.594 \\
\hline CHIND & 4.217 & 11.998 & -7.688 & -12.884 & -2.429 \\
\hline RoW & 2.490 & 7.085 & -4.540 & -7.608 & -1.435 \\
\hline
\end{tabular}

Scenarios of climate change predict an increase in average regional temperatures, bringing about an increase in consumption of energy goods in the summer and a decrease in the winter. The net effect, on an annual basis, is a reduction of energy consumption (with the exception of coal, whose direct consumption levels by households are, however, negligible).

The lower demand for energy goods would generate a drop in world prices of energy. Also, savings in household energy expenditure would allow an increase in spending for other goods and services. Income levels and prices of primary resources would be affected as well. The next section illustrates how a Computable General Equilibrium model can be used to assess these systemic effects.

\section{Simulating the general equilibrium effects of changes in energy demand}

Demand for energy goods, like demand for any other good and factor, is a naturally endogenous variable in a general equilibrium model, as it depends on income and relative prices. In order to shift demand at constant prices and income, an exogenous variation in some structural parameters of utility or production functions is needed. This has two important consequences. First, in a general equilibrium, the ex-ante variation of demand differs from the ex-post variation, since the latter takes price adjustments into account. Second, in order to meet the budget constraint for every agent, any exogenous shift in the demand for some item has to be compensated by shifts in the demand for other items.

In order to simulate the effects of a changing demand for energy goods, we have introduced and shocked specific shifting factors in the equation describing the demand for goods and factors in a Computable General Equilibrium (CGE) model of the world economy. ${ }^{3}$ This model is the popular GTAP model v.6 (Hertel, 1996) in the alternative formulation GTAP-E, originally proposed by Burniaux and Truong

3 We modified the equation expressing the demand for energy goods in such a way that, if prices and income would stay constant, the demand would change according to the estimates illustrated in Section 2. We also introduced shifting factors in the demand for all other goods and factors. These factors are endogenously adjusted by the model, such that an explicit budget constraint holds. 
Structural parameters in the GTAP model are obtained by a standard calibration procedure. This means that parameters are selected such that the model replicates the observed structure of the world economy, as described in a calibration data- set (year 2001). One problem of our application is given by the fact that we are interested in simulating changes occurring in the future, which means that our benchmark should refer to a 2050 scenario, not to a 2001 data- set.

To this end, we derived hypothetical data for 2050, using the methodology described in Dixon and Rimmer (2002). This entails inserting, in the model calibration data, forecasted values for some key economic variables: national endowments of labour, capital, land, natural resources, as well as factor and multifactor productivity.

In this way, we got a reference equilibrium state, that can subsequently be perturbed by exogenous shocks. Therefore, by changing the structure of demand for households and firms, we can run a conventional comparative static exercise, providing information about the systemic, net effect of exogenous changes in "tastes" and "technologies". This information comes in terms of: variations in industrial output, national income, trade flows, foreign debt, welfare and other variables.

Notice that the shock is due to a changing composition of demand, not to variations in endowments of primary resources. This implies that, at the global level, the shock is neither positive nor negative, and the main effects are distributional: differences in relative income, welfare and competitiveness.

Table 3 shows percentage variations in some main economic aggregates, generated by the simulation exercise. Tables A1 and A2 in the Appendix show variations in prices and quantities of all goods and factors, including energy commodities.

The most important driving force behind the results is, clearly, the change in the terms of trade induced by the drop in the world demand for energy goods. This benefits energy importing countries and harms energy exporting countries. Second order effects are also at work, trough exogenous shifts in demand for non-energy goods and services, so that the overall impact on GDP and utility depends on the comparative advantage characteristics of each region. In Europe, for example, there are gains in the terms of trade, but nonetheless GDP and household utility both decline.

Real investment is allocated worldwide, in the model, according to expected future returns on capital. Since future returns are linked to current returns, and energy industries are relatively capital-intensive, the falling energy prices bring about falls

4 A CGE model provides an internally consistent and detailed description of an economic system, highlighting trade linkages between industries, regions and markets. CGE models are primarily used to simulate and assess the structural adjustments, undertaken by economic systems as a consequence of shocks, like changes in technology, preferences or economic policy. The mathematical structure of a CGE model can be very complex. The GTAP model is composed of hundreds of equations, defining market-clearing conditions, accounting identities, zero- profit conditions or behavioural relationships, in more than 5000 lines of computer code. The reader interested about the details of the GTAP model should refer to Hertel (ibid.), and to the technical material available on the GTAP site (www.gtap.org). 
in capital returns, and drops in investment, particularly in energy exporting countries. This effect contribute to the overall variation in the GDP.

The model also estimates variations in emissions of carbon dioxide, although this is a purely descriptive variable, with no effect on the economic equilibrium of this specific simulation. The last column of Table 3 shows that variations in $\mathrm{CO}^{2}$ emissions are negative, as expected, and quite significant.

Table 3 -Results - Main Economic Aggregates

\begin{tabular}{|l|c|c|c|c|c|}
\hline Regions & GDP & Investment & $\begin{array}{c}\text { Terms of } \\
\text { Trade }\end{array}$ & $\begin{array}{c}\text { Household } \\
\text { Utility }\end{array}$ & $\mathrm{CO}^{2}$ Em. \\
\hline USA & 0.034 & -0.047 & 0.236 & 0.031 & -2.378 \\
\hline EU & -0.256 & 0.060 & 0.110 & -0.201 & -3.167 \\
\hline EEFSU & -0.549 & -0.458 & -0.395 & -0.279 & -2.584 \\
\hline JPN & 0.011 & 0.007 & 0.392 & -0.073 & -1.406 \\
\hline RoA1 & -0.316 & -0.100 & -0.158 & -0.179 & -2.710 \\
\hline EEx & -0.882 & -0.647 & -1.074 & -0.347 & -1.135 \\
\hline CHIND & -0.028 & -0.572 & 0.236 & -0.052 & -0.362 \\
\hline RoW & 0.012 & -0.021 & 0.288 & 0.052 & -0.353 \\
\hline
\end{tabular}

\section{Introducing market power in energy industries}

Although conventional CGE models are based on the Walrasian paradigm, it is not necessary that all markets are perfectly competitive, for a CGE model to produce meaningful results. As mentioned above, almost all CGE models are calibrated on real data sets, which certainly reflect existing market imperfections. Therefore, baseline market failures are (to some extent) "embedded", "frozen" into the model, so that the neoclassical paradigm is only used as a sort of "theoretical engine", leading the adjustment of the economic structure from one state to another.

Yet, the existence of market power in industries producing energy goods should be carefully assessed. In fact, energy industries are perhaps the farthest away from the competitive paradigm: economies of scale, barriers to entry, regulatory regimes, sunk costs, limited number of competitors, etc., are typical characteristics of these industries throughout the world. So the question is not whether energy industries are competitive, but whether the reaction of the model to any exogenous shock becomes (significantly) different when market power is explicitly taken into account.

The answer to this question relies on how imperfect competition is introduced in the CGE model. This issue is discussed at length in Roson (2006), pointing out that there is no single way of implementing imperfect competition in CGE models, and that alternative solutions could lead to quite different results. This is because, to start with, there are a number of alternative oligopolistic models in industrial organization theory and, furthermore, translating some concepts from partial to general equilibrium involves additional difficulties. 
The model which is used here assumes oligopolistic competition à la Cournot (only in energy industries) between symmetric firms, blocked entry and constant returns to scale. We chose this specification because the number of competitors in most energy markets can be assumed as given in the short run, and because economies of scale, although possibly relevant at the plant level, may not play a very important role within broad geographical and sectoral aggregates.

We estimated the initial amount of unitary profits, for energy industries, using a variety of sources (Oliveira- Martins et al. (1996), Maioli (2003), Barbu et al. (2003), OXERA (2003)), combining econometric estimations of profit mark-ups, for some counties and industries, with indexes of market concentration and competitiveness. In official national accounts, profits are typically included inside a broad residual element, which also includes payments on capital services. Correspondingly, we split calibration data for capital inputs in two separate components: "capital" and "profit". Table 4 shows the split parameters used to this purpose.

Table 4-Profit shares in the profit-capital aggregates
\begin{tabular}{|l|c|c|c|c|c|}
\hline Regions & Coal & Oil & Gas & $\begin{array}{c}\text { Oil. } \\
\text { Prod. }\end{array}$ & $\begin{array}{c}\text { Electricit } \\
\mathbf{y}\end{array}$ \\
\hline USA & 0.560 & 0.612 & 0.557 & 0.900 & 0.565 \\
\hline EU & 0.758 & 0.207 & 0.224 & 0.877 & 0.458 \\
\hline EEFSU & 0.241 & 0.081 & 0.105 & 0.647 & 0.783 \\
\hline JPN & 0.818 & 0.522 & 0.731 & 0.585 & 0.717 \\
\hline RoA1 & 0.477 & 0.900 & 0.900 & 0.900 & 0.900 \\
\hline EEx & 0.224 & 0.285 & 0.375 & 0.990 & 0.841 \\
\hline CHIND & 0.617 & 0.377 & 0.612 & 0.900 & 0.924 \\
\hline RoW & 0.415 & 0.339 & 0.317 & 0.675 & 0.536 \\
\hline
\end{tabular}

In this model, like in any oligopolistic model, profit margins are inversely related to price demand elasticities. Roson (ibid.) shows how industrial and individual demand elasticities can be computed from elasticity of substitution parameters used in the CGE model. When a representative firm sells in a number different regional markets, the demand elasticity can be expressed as a weighted sum of regional elasticities, where the weights are given by market shares. In this simulation exercise, we are simulating exogenous shifts in the households demand for energy goods. Since these shifts are not proportional in all markets, they will directly affect the regional market shares, the aggregate demand elasticities, the unitary profits and ultimately the final market price for energy goods.

In addition, there are important secondary effects at work, related to changes in prices of input factors. The demand shifts create a general reduction of energy demand. In turn, this generates a reduction of demand for those factors, in which energy industries are relatively intensive, like natural resources and capital. Roson (ibid.) discusses why cost shocks are likely to be amplified in a CGE model with 
imperfect competition, in comparison with a conventional model formulation, based on perfect competition. This effect is related to the endogenous variation of market shares. However, the model has been recalibrated here, by assuming unitary profits in the baseline equilibrium, implying reduced cost shares for capital (in comparison with the PC closure). This means that the induced decrease in the price of capital will be smaller, as well as that any change in the price of this factor will have smaller consequences on energy prices.

Table 5 summarizes how the various model characteristics, discussed above, may affect the results of the simulation exercise, in comparison with the standard, perfect competition setting.

Table 5 - Key characteristics of the IC model version, amplifying (+) or dampening (-) the impact of variations in energy demand, in comparison with the PC model version

\begin{tabular}{|l|c|}
\hline Key Characteristics & Effect \\
\hline Exogenous variation of market shares & $?$ \\
\hline Endogenous variation of market shares & + \\
\hline $\begin{array}{l}\text { Lower shares of capital in the price } \\
\text { structure }\end{array}$ & - \\
\hline
\end{tabular}

Tables A3 and A4 in the Appendix show percentage changes in quantities and prices under imperfect competition, corresponding to Tables A1 and A2.

Table 6 shows how industrial demand elasticities changes after the variations in households' demand. Higher elasticities imply less market power and lower profit mark-ups. However, changes in market power play a relatively minor role in influencing price changes under imperfect competition, in a comparison with perfect competition. Rather, whenever the price of capital is higher in imperfect competition, than in perfect competition, then prices of energy goods also tend to be higher. Furthermore, recall that the simulated shock produces here less effects on the price of capital, because capital has a lower cost share in the production of energy goods.

Table 6 -Percentage changes in industrial demand elasticities

\begin{tabular}{|l|c|c|c|c|c|c|c|c|}
\hline $\begin{array}{l}\text { Industri } \\
\text { es }\end{array}$ & USA & EU & EEFSU & JPN & RoA1 & EEx & CHIND & RoW \\
\hline Coal & 1.94 & 0 & -1.66 & -0.09 & 0.44 & 0.29 & -1.63 & -0.05 \\
\hline Oil & 0.09 & -0.08 & 1.52 & 0 & -0.03 & -1.09 & 1.34 & -0.5 \\
\hline Gas & -0.43 & 0.11 & 1.22 & 0 & -0.14 & -1.07 & 0.18 & -0.01 \\
\hline Oil.Prod. & 0.75 & 0.53 & 3.22 & -0.87 & 0.34 & 0 & 0.63 & -1.06 \\
\hline Electricity & -0.6 & -0.66 & 1.42 & -2.25 & -0.87 & 1.81 & -0.1 & -0.98 \\
\hline
\end{tabular}

Figure 1 provides a graphical illustration of the price-quantity movements in the two model versions, for energy goods. The simulated shock imply a backward shift in the demand for energy, lowering both prices and produced quantities of energy goods. This can be observed in both cases. However, prices fall less under imperfect 
competition, whereas quantities may fall more or less (in the figure, quantity is assumed to be roughly the same). In the figure, three hypothetical points are considered: a baseline combination of price and quantity, and two price- quantity pairs obtained in the two market regimes (IC and PC). The result obtained under imperfect competition can be interpreted as a the outcome produced by a backward shift in demand, smaller than that observed in perfect competition, and an upward shift in the supply curve of energy goods.

The demand shift is smaller because households' income is relatively higher, as the latter includes profits and capital income (as well as rents on natural resources). The shift in supply is due to relatively higher production "costs": higher cost of capital and possibly higher unitary profits.

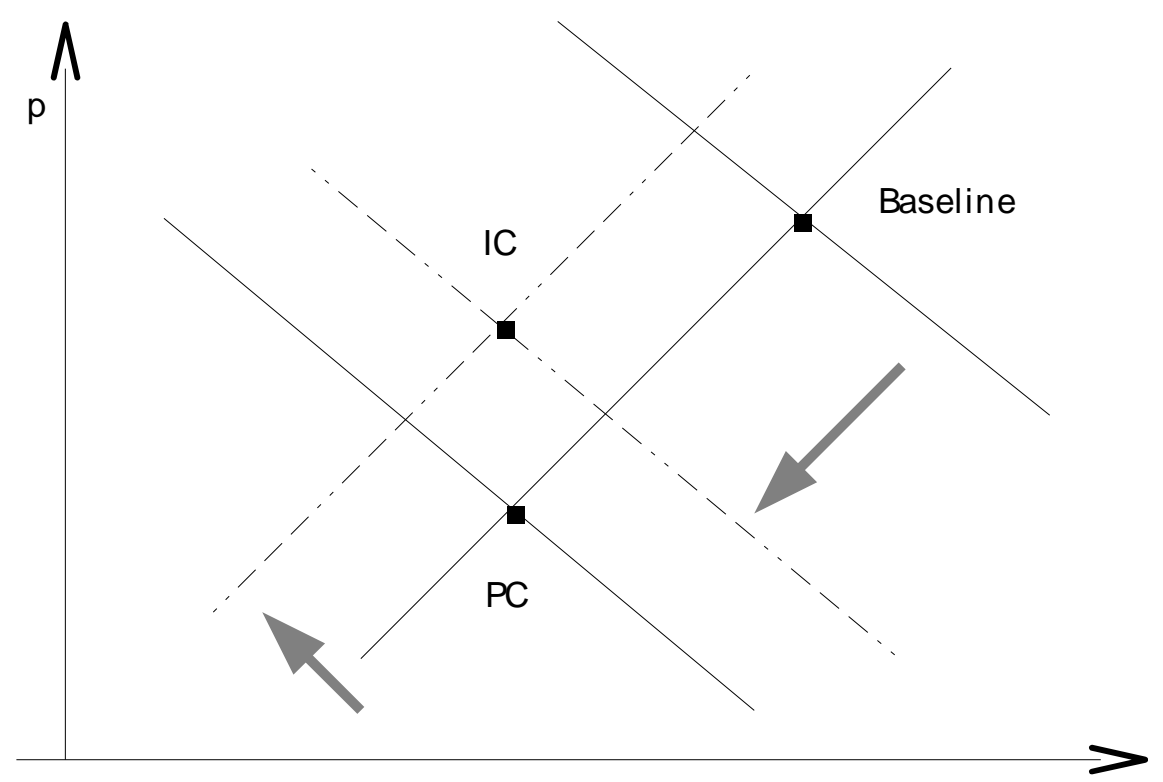

q

Figure $1-A n$ illustrative diagram of relative price-quantity movements in energy industries

Table 7 shows the regional Equivalent Variations (EV)computed for two cases. The EV is a money-metric measure of changes in utility for the representative household. It considers which changes in income, at constant prices, would produce the same effects on utility of the simultaneous changes in income and prices, simulated in the two scenarios. We can see that effects are globally negative, and generally worse in imperfect competition. Only two regions seem to get net benefits, although quite small: the USA and the Rest of the World. This result is due to a complex combination of factors: changes in the terms of trade, structure of preferences, income sources, and other features. 
Table 7 - Equivalent Variations in the two model versions ${ }^{5}$

\begin{tabular}{|l|c|c|}
\hline Regions & IC & PC \\
\hline USA & 1856 & 7191 \\
\hline EU & -52262 & -46768 \\
\hline EEFSU & -11587 & -9609 \\
\hline JPN & -9072 & -8850 \\
\hline RoA1 & -10935 & -7954 \\
\hline EEx & -39360 & -32921 \\
\hline CHIND & -5172 & -2545 \\
\hline RoW & 3740 & 6223 \\
\hline WORLD & -122792 & -95233 \\
\hline
\end{tabular}

\section{Conclusion}

Climate change will have a direct impact on the demand for energy, since the latter is affected by average temperature levels. In this paper, we presented some results obtained by a world CGE model, simulating exogenous changes in the households' demand structure. Our exercise was based on previous findings of an econometric model, suggesting that higher temperatures may bring about lower consumption of most energy goods and higher consumption of other goods and services, at constant prices and income.

Results have been obtained in the CGE model, by imposing an exogenous change in the households' structure of preferences. These results highlight variations in the terms of trade, benefiting energy importing countries and harming energy exporting countries, and falls in prices of energy goods, capital services and natural resources.

These findings are robust in terms of market structure specification. We repeated the experiment with an alternative model version, where we assumed that energy industries were Cournot oligopolies, with profits in both the baseline and counterfactual equilibria. Although the model simulates changes in market power for the various regional industries, most of the differences in results between the two model versions can be interpreted as consequences of different cost shares for capital in the model calibration. We found that lower capital shares, under imperfect competition, imply smaller price reductions for energy goods, but higher utility losses worldwide.

\section{Acknowledgements}

This work is part of a collaborative research on the economic impacts of climate changes, jointly carried out by Fondazione Eni Enrico Mattei, Italy, and the Research unit Sustainability and Global Change of Hamburg University, Germany.

5 Millions of 2001 US \$. 


\section{References}

Barbu, D., Kalashnikov, V. and C. Kemfert, (2003), Economic Effects of the Liberalization of the European Electricity Market-Simulation Results of a Game Theoretic Modelling Concept, Mimeo, DIW Berlin.

Berrittella, M., Bigano, A., Roson, R., and R.S.J. Tol, (2005a), "A General Equilibrium Analysis of Climate Change Impacts on Tourism", Tourism Management, forthcoming.

Berrittella, M., Hoekstra, A., Rehdanz, K., Roson, R. and R.S.J. Tol, (2005b), The Economic Impact of Restricted Water Supply: a Computable General Equilibrium Analysis, FNU-93, Hamburg University and Centre for Marine and Atmospheric Science, Hamburg.

Bigano, A., Bosello, F., and G. Marano (2006), Energy Demand and Temperature: a Dynamic Panel Analysis, Mimeo, Fondazione ENI Enrico Mattei. Forthcoming as FEEM working paper.

Bosello, F., Lazzarin, M., Roson, R., and R.S.J. Tol, (2004), Economy- Wide Estimates of the Implications of Climate Change: Sea-Level Rise, FEEM working paper n.96.2004.

Bosello, F., Roson, R., and R.S.J. Tol, (2006) , "Economy- Wide Estimates of the Implications of Climate Change: Human Health", Ecological Economics, forthcoming.

Burniaux, J.- M., and Truong, T.P., (2002), GTAP-E: an Energy Environmental Version of the GTAP Model, GTAP Technical Paper n.16.

Calzadilla, A., Pauli, F., and R. Roson (2005), Climate Change and Extreme Events: an Assessment of Economic Implications, EEE-ICTP working paper.

Dixon, P., and M. Rimmer, (2002) Dynamic General Equilibrium Modeling for Forecasting and Policy, Amsterdam: North Holland.

Giorgi, F., and L.O. Mearns, (2002), "Calculation of Average, Uncertainty Range and Reliability of Regional Climate Changes from AOGCM Simulations via the REA Method", American Meteorology Society, vol. 15, pp. 1141-1158.

Hertel, T.W., (1997), Global Trade Analysis: Modeling and applications, Cambridge University Press, Cambridge.

Maioli, S. (2003), A Joint Estimation of Markups and Returns to Scale in 22 French Industries: A Structural Approach, Mimeo, GEP University of Nottingham, U.K.

Oliveira-Martins, J., Pilat, D. and S. Scarpetta (1996), Mark-up ratios in manufacturing industries: Estimates for 14 OECD countries, OECD Economics Department Working Papers No. 162. 
OXERA (2003), Energy Market Competition in the EU and G7: the relative extent of energy market competition in the EU and G7, Report for the UK Department of Trade and Industry.

Pardo, A., Meneu, V., Valor, E., (2002), “Temperature and Seasonality Influences on Spanish Electricity Load”, Energy Economics, vol.24, pp. 55-70.

Roson, R., (2006) "Introducing Imperfect Competition in CGE Models: Technical Aspects and Implications", Computational Economics, forthcoming. 
Appendix - Additional Simulation Results

Table A1 - Results (Perfect Competition) - Industry production volumes (\% change)

\begin{tabular}{|l|c|c|c|c|c|c|c|c|}
\hline & USA & EU & EEFSU & JPN & RoA1 & EEx & CHIND & RoW \\
\hline Rice & 0.11 & 0.36 & 0.5 & 0.05 & 0.27 & 0.5 & 0.12 & 0.01 \\
\hline Wheat & 0.01 & 0.01 & 0.25 & 0.05 & 0.07 & 0.41 & 0.15 & 0.06 \\
\hline CerCrops & 0.06 & 0.12 & 0.27 & 0.21 & 0.21 & 0.14 & -0.04 & 0.18 \\
\hline VegFruits & 0.07 & 0.19 & 0.24 & 0.2 & 0.25 & 0.13 & 0.12 & 0.14 \\
\hline Animals & 0.02 & 0.07 & 0.29 & 0.07 & 0.16 & 0.3 & 0.16 & 0.08 \\
\hline Forestry & -0.02 & -0.03 & 0.55 & 0.02 & 0.16 & 0.41 & 0.29 & 0.1 \\
\hline Fishing & 0.07 & 0.19 & 0.71 & 0.16 & 0.25 & 0.34 & 0.31 & 0.15 \\
\hline Coal & -0.57 & -0.24 & 0.87 & -0.26 & -0.18 & 0.39 & 0.46 & -0.16 \\
\hline Oil & -2.92 & -4.15 & -4.42 & -4.85 & -3.43 & -2.46 & -1.84 & -2.66 \\
\hline Gas & -2.28 & -5.08 & -3.62 & -5.93 & -1.72 & -1.07 & -1.2 & -1.84 \\
\hline Oil_Pcts & -3.69 & -4.2 & -5.52 & -3.7 & -3.3 & -1.13 & -3.35 & -1.41 \\
\hline Electricity & -1.14 & -1.68 & -0.92 & -1.02 & -1.5 & -0.31 & -0.71 & -0.7 \\
\hline Water & 0.11 & 0.16 & 0.33 & 0.09 & 0.04 & 0.13 & 0.25 & 0.16 \\
\hline En_Int_ind & -0.07 & 0.02 & 0.96 & -0.09 & 0.23 & 0.77 & 0.22 & -0.04 \\
\hline Oth_ind & 0 & 0.03 & 0.5 & 0.03 & 0.26 & 0.6 & -0.06 & -0.03 \\
\hline MServ & 0.11 & 0.17 & 0.55 & 0.11 & 0.18 & 0.18 & 0.17 & 0.13 \\
\hline NMserv & -0.02 & -0.21 & -0.37 & -0.09 & -0.26 & -0.24 & 0.08 & 0 \\
\hline
\end{tabular}

Table A2 - Results (Perfect Competition) - Prices of primary resources, goods and factors (\% change)

\begin{tabular}{|l|c|c|c|c|c|c|c|c|}
\hline & USA & EU & EEFSU & JPN & RoA1 & EEx & CHIND & RoW \\
\hline Land & 0.89 & 1.12 & 2.47 & 1.12 & 1.63 & 2.01 & 1.82 & 1.23 \\
\hline Labour & 0.01 & 0 & -0.19 & 0.15 & -0.11 & -0.83 & -0.62 & -0.06 \\
\hline Capital & 0.04 & 0.13 & -0.49 & 0.17 & -0.12 & -0.91 & -0.57 & 0.03 \\
\hline Natural Res. & -12.07 & -5.64 & -9.95 & 0.06 & -9.25 & -12.05 & -5.33 & -2.91 \\
\hline Rice & 0.68 & 0.78 & 1.38 & 0.59 & 0.88 & 1.32 & 1.2 & 0.83 \\
\hline Wheat & 0.57 & 0.66 & 0.97 & 0.58 & 0.61 & 0.49 & 1.05 & 0.5 \\
\hline CerCrops & 0.65 & 0.71 & 0.97 & 0.55 & 0.75 & 0.8 & 1.14 & 0.69 \\
\hline VegFruits & 0.62 & 0.69 & 1 & 0.54 & 0.7 & 0.81 & 1.19 & 0.65 \\
\hline Animals & 0.58 & 0.68 & 0.99 & 0.51 & 0.75 & 0.65 & 1.24 & 0.57 \\
\hline Forestry & -0.01 & -0.01 & -0.16 & 0.01 & -0.05 & -0.45 & -0.02 & 0.08 \\
\hline Fishing & -0.19 & 0.03 & -0.47 & -0.34 & -0.18 & -0.73 & -0.04 & -0.17 \\
\hline Coal & -0.46 & -0.27 & 0.9 & 0.01 & -0.23 & -0.37 & 0.19 & -0.18 \\
\hline Oil & -4.34 & -4.11 & -4.78 & -3.38 & -4.18 & -4.22 & -4.98 & -3.59 \\
\hline Gas & -0.06 & -0.59 & -1.68 & -0.49 & -0.82 & -1.14 & -1.06 & -0.39 \\
\hline Oil_Pcts & -3.13 & -3.35 & -4.24 & -1.84 & -3.52 & -3.74 & -3.66 & -3.07 \\
\hline Electricity & -0.11 & -0.16 & -1.4 & -0.06 & -0.2 & -1.59 & -0.66 & -0.44 \\
\hline Water & 0 & 0.02 & -0.44 & 0.12 & -0.12 & -0.86 & -0.46 & -0.11 \\
\hline En_Int_ind & -0.1 & -0.18 & -0.55 & -0.06 & -0.25 & -0.71 & -0.34 & -0.15 \\
\hline Oth_ind & 0.1 & 0.12 & 0.01 & 0.13 & 0.04 & -0.22 & 0.18 & 0.12 \\
\hline MServ & 0 & -0.01 & -0.32 & 0.12 & -0.14 & -0.75 & -0.28 & -0.06 \\
\hline NMserv & 0.02 & 0.01 & -0.23 & 0.11 & -0.11 & -0.65 & -0.36 & -0.03 \\
\hline
\end{tabular}


Table A3 - Results (Imperfect Competition) - Industry production volumes (\% change)

\begin{tabular}{|l|c|c|c|c|c|c|c|c|}
\hline & USA & EU & EEFSU & JPN & RoA1 & EEx & CHIND & RoW \\
\hline Rice & 0.1 & 0.33 & 0.47 & 0 & 0.21 & 0.45 & 0.1 & 0.01 \\
\hline Wheat & 0 & 0 & 0.23 & 0.05 & 0.06 & 0.37 & 0.13 & 0.05 \\
\hline CerCrops & 0.05 & 0.1 & 0.24 & 0.18 & 0.18 & 0.13 & -0.05 & 0.16 \\
\hline VegFruits & 0.07 & 0.18 & 0.23 & 0.19 & 0.22 & 0.11 & 0.1 & 0.12 \\
\hline Animals & 0.02 & 0.06 & 0.27 & 0.03 & 0.12 & 0.27 & 0.15 & 0.07 \\
\hline Forestry & -0.03 & -0.03 & 0.51 & -0.01 & 0.11 & 0.34 & 0.24 & 0.08 \\
\hline Fishing & 0.06 & 0.18 & 0.67 & 0.12 & 0.19 & 0.28 & 0.28 & 0.14 \\
\hline Coal & -0.52 & -0.18 & 0.88 & -0.15 & -0.18 & 0.36 & 0.47 & -0.09 \\
\hline Oil & -2.73 & -3.83 & -4.27 & -4.31 & -3.21 & -2.35 & -1.74 & -2.41 \\
\hline Gas & -2.23 & -4.9 & -3.63 & -5.85 & -1.72 & -1.15 & -1.21 & -1.63 \\
\hline Oil_Pcts & -3.85 & -4.33 & -5.64 & -3.74 & -3.53 & -1.42 & -3.5 & -1.52 \\
\hline Electricity & -1.14 & -1.62 & -1.02 & -0.98 & -1.62 & -0.5 & -0.79 & -0.66 \\
\hline Water & 0.09 & 0.15 & 0.26 & 0.07 & -0.05 & 0.04 & 0.17 & 0.14 \\
\hline En_Int_ind & -0.08 & 0.03 & 0.89 & -0.13 & 0.1 & 0.67 & 0.16 & -0.04 \\
\hline Oth_ind & 0 & 0.03 & 0.47 & -0.03 & 0.18 & 0.54 & -0.09 & -0.02 \\
\hline MServ & 0.09 & 0.15 & 0.5 & 0.09 & 0.11 & 0.1 & 0.13 & 0.1 \\
\hline NMserv & -0.03 & -0.23 & -0.43 & -0.09 & -0.32 & -0.31 & -0.01 & -0.02 \\
\hline
\end{tabular}

Table A4 - Results (Imperfect Competition) - Prices of primary resources, goods and factors (\% change)

\begin{tabular}{|l|c|c|c|c|c|c|c|c|}
\hline & USA & EU & EEFSU & JPN & RoA1 & EEx & CHIND & RoW \\
\hline Land & 0.74 & 0.98 & 2.24 & 0.82 & 1.34 & 1.76 & 1.61 & 1.06 \\
\hline Labour & 0 & -0.01 & -0.2 & 0.16 & -0.12 & -0.82 & -0.56 & -0.06 \\
\hline Capital & 0.07 & 0.14 & -0.41 & 0.22 & 0.03 & -0.8 & -0.44 & 0.04 \\
\hline Natural Res. & -11.39 & -5.26 & -9.68 & -0.07 & -8.82 & -11.47 & -5.04 & -2.64 \\
\hline Rice & 0.57 & 0.68 & 1.25 & 0.44 & 0.73 & 1.14 & 1.06 & 0.72 \\
\hline Wheat & 0.47 & 0.57 & 0.87 & 0.45 & 0.51 & 0.4 & 0.94 & 0.43 \\
\hline CerCrops & 0.55 & 0.62 & 0.86 & 0.44 & 0.63 & 0.68 & 1.01 & 0.6 \\
\hline VegFruits & 0.53 & 0.61 & 0.9 & 0.44 & 0.59 & 0.69 & 1.06 & 0.56 \\
\hline Animals & 0.48 & 0.59 & 0.89 & 0.41 & 0.63 & 0.54 & 1.1 & 0.49 \\
\hline Forestry & -0.02 & -0.01 & -0.15 & 0.02 & -0.07 & -0.44 & -0.02 & 0.07 \\
\hline Fishing & -0.18 & 0.04 & -0.44 & -0.32 & -0.15 & -0.68 & -0.03 & -0.15 \\
\hline Coal & -0.43 & -0.23 & 0.93 & 0.05 & -0.16 & -0.27 & 0.29 & -0.11 \\
\hline Oil & -4.1 & -3.84 & -4.58 & -3.06 & -3.91 & -3.89 & -4.61 & -3.28 \\
\hline Gas & -0.06 & -0.58 & -1.61 & -0.47 & -0.76 & -0.96 & -0.89 & -0.35 \\
\hline Oil_Pcts & -2.93 & -3.12 & -4.04 & -1.7 & -3.28 & -3.39 & -3.36 & -2.83 \\
\hline Electricity & -0.11 & -0.17 & -1.29 & -0.09 & -0.12 & -1.27 & -0.46 & -0.4 \\
\hline Water & 0 & 0.03 & -0.41 & 0.15 & -0.05 & -0.8 & -0.37 & -0.1 \\
\hline En_Int_ind & -0.09 & -0.17 & -0.52 & -0.02 & -0.2 & -0.65 & -0.29 & -0.14 \\
\hline Oth_ind & 0.09 & 0.11 & 0 & 0.14 & 0.04 & -0.22 & 0.17 & 0.11 \\
\hline MServ & 0 & -0.01 & -0.3 & 0.14 & -0.1 & -0.7 & -0.24 & -0.05 \\
\hline NMserv & 0.01 & 0.01 & -0.23 & 0.13 & -0.08 & -0.63 & -0.31 & -0.03 \\
\hline
\end{tabular}

